\title{
OsATG8c-Mediated Increased Autophagy Regulates the Yield and Nitrogen Use Efficiency in Rice
}

\author{
Xiaoxi Zhen, Xin Li, Jinlei Yu and Fan $\mathrm{Xu}$ *
}

Key Laboratory of Northern Japonica Rice Genetics and Breeding, Ministry of Education and Liaoning Province, Key Laboratory of Northeast Rice Biology and Genetics and Breeding, Ministry of Agriculture, Rice Research Institute of Shenyang Agricultural University, Shenyang 110866, China; xiaoxizhen1991@163.com (X.Z.); lixin241910@163.com (X.L.); yujinlei0628@163.com (J.Y.)

* Correspondence: celiafanfan@163.com or celiafanfan@syau.edu.cn; Tel.: +86-186-9889-2843

Received: 18 September 2019; Accepted: 27 September 2019; Published: 8 October 2019

check for updates

\begin{abstract}
Autophagy, a conserved pathway in eukaryotes, degrades and recycles cellular components, thus playing an important role in nitrogen $(\mathrm{N})$ remobilization. $\mathrm{N}$ plays an important role in the growth and development of plants, which also affects plant yield and quality. In this research, it was found that the transcriptional level of a core autophagy gene of rice (Oryza sativa), OsATG8c, was increased during $\mathrm{N}$ starvation conditions. It was found that the overexpression of OsATG8C significantly enhanced the activity of autophagy and that the number of autophagosomes, dwarfed the plant height and increased the effective tillers' number and yield. The nitrogen uptake efficiency (NUpE) and nitrogen use efficiency (NUE) significantly increased in the transgenic rice under both optimal and suboptimal $\mathrm{N}$ conditions. Based on our results, OsATG8c is considered to be a good candidate gene for increasing NUE, especially under suboptimal field conditions.
\end{abstract}

Keywords: OsATG8c; nitrogen use efficiency (NUE), yield; autophagy; rice

\section{Introduction}

Autophagy is a conserved vacuolar degradation pathway by which cells recycle components, including unwanted macromolecular substances or damaged organelles. The nutrients are mobilized and reused for the maintenance of cellular processes and adaptation to stress [1]. The first AuTophaGy-related gene (ATG gene) was identified in yeast [2]. Subsequently, many ATG genes have also been characterized in different species, including mammals and plants [3-5]. In Arabidopsis (Arabidopsis thaliana), most ATG genes are transcriptionally up-regulated during leaf senescence and nutrient starvation [6-8]. Among mammals, yeasts and plants, the identified proteins are responsible for the core autophagic mechanism [9].

Autophagy controls the remobilization of nitrogen $(\mathrm{N})$ from leaves to seeds and was first discovered in Arabidopsis atg mutants [10]. The Arabidopsis wild type (WT) and atg mutants (atg18a RNAi, atg5, and $\operatorname{atg} 9$ ) were fed ${ }^{15} \mathrm{NO}_{3}{ }^{-}$during the vegetative growth stage. Under $\mathrm{N}$ stress, all atg mutants showed that ${ }^{15} \mathrm{~N}$ remobilization sharply decreased compared to WT, and the nitrogen use efficiency (NUE) from leaves to seeds decreased significantly, by nearly to $50 \%$ [11]. In addition, some studies revealed that the atg mutants (Arabidopsis, maize, and rice) have a premature senescence phenotype, which changes the metabolome and protein accumulation of cells, reducing the biomass, yield, and tolerance to biotic and abiotic stress [12-14]. Through a ${ }^{15} \mathrm{~N}$ pulse-chase analysis it was shown, that the maize atg mutant is unable to mobilize $\mathrm{N}$ from senescent leaves to seeds and has a reduced NUE compared with control plants [15]. Subsequent studies have also found that autophagy takes part and plays an important role in the formation of eukaryotic proteins and membranes [16]. 
Plants are sedentary and cannot move to acquire nutrients and minerals as needed. Their survival depends on their ability to consume the mineral nutrients available in the rhizosphere and metabolize, recycle, and conserve them efficiently during their lifespan $[17,18]$. Nitrogen $(\mathrm{N})$ is the most important nutrient for plant development and growth and is also a vital component of macromolecules in cells. In cereal crops, $\mathrm{N}$ mobilization from aging leaves has an important effect on the grain yield and quality [19-21]. The grain yield of rice is mainly determined by the number of panicles per plant, the number of grains per panicle, and the grain weight, while the panicle number is dependent on the rice tillering ability [22]. Tillering in crops is regulated by genetic, hormonal, developmental, and environmental factors [23,24]. Previous studies have identified numerous genes related to tillering regulation in rice. $M O C 1$ was the first gene characterized for rice tillering, and it functions to initiate axillary buds [25]. OSTB1/FC1 and OsSPL14 have been reported to repress rice tillering [26,27]. Genes related to the biosynthesis and signaling of strigolactones, such as the DWARF genes D3 [28], D17/HTD1 [29], D10/OsMAX4 [30], D14/HTD2 [31], D27 [32], and D53 [33] have been suggested to be involved in tillering regulation in rice. The cytokinin oxidase/dehydrogenase (CKX) enzyme coding gene $O s C K X 2$ negatively regulates the tiller number and grain yield in rice [34,35], whereas the indole-3-acetic acid (IAA)-glucose synthase gene OsIAGLU positively affects tillering [36]. Recent research shows that the overexpression of OsSta2 and the rice nitrate-transporter gene OsNPF7.2 can increase the tiller number and yield in rice [37,38], while reduced expression of OsAAP3 can also significantly increase the tiller number [39].

ATG8 is a ubiquitin-like protein, which is located on the membrane of the autophagosome $[40,41]$. ATG8 is often used as a reliable marker of autophagic activity in plants and animals [42,43]. Due to providing a docking site for autophagic receptors, which contains the ATG8 interaction motif (AIM) and selects the degraded cargo, ATG8 acts as a central component in autophagy. The first identified ATG8 in rice was OsATG8a, which interacts with ATG4 [44]. OsATG8a, OsATG8b, and OsATG8c have high homology, while OsATG8d is similar to AtATG8i $[45,46]$. It was shown that the overexpression of ATG8s from different plants, such as AtAtg8f, MdATG8i, GmATG8c, and SiATG8a, led to better growth and promoted tolerance to N-limited stress [47-51]. Recently, it was showed that the AtATG8s (AtATG8a, AtATG8e, AtATG8f, or AtATG8g)-overexpressing transgenic Arabidopsis increased the autophagosome number, stimulated autophagic activity, and increased the $\mathrm{N}$ remobilization efficiency (NRE) under full $\mathrm{N}$ conditions but did not affect the yield and biomass [52]. Our own contemporaneous research also found that the overexpression of OsATG8a in rice could increase the autophagic flux, grain yield, and NUE [53].

In this study, we investigated the potential functions of the OsATG8c gene (LOC_Os08g09240) of rice. This gene has a $363 \mathrm{bp}$ coding sequence (CDS) and encodes 121 amino acids. The OsATG8c protein was localized to the cytoplasm. We then confirmed its function using $35 S-O s A T G 8 c$ in transgenic rice plants. The independent transgenic lines were found to promote the effective tillering of rice and produce more ears and seeds, thus increasing the yield. Meanwhile, autophagic flux was significantly enhanced in the OsATG8c-overexpressors under both nitrogen sufficient and deficient conditions. It was also shown that the overexpression of OsATG8c significantly enhanced the nitrogen uptake efficiency (NUpE) and NUE under both $\mathrm{N}$ conditions. Therefore, our results indicate that OsATG8c may be an important candidate gene for rice with increased NUE and better grain yield potential.

\section{Results}

\subsection{The Expression Patterns of the OsATG8c Gene in Rice}

Histochemical analysis was performed to examine the temporal and spatial expression patterns of OsATG8c in Pro $_{O s A T G 8 c}$-GUS transgenic rice. It was proved that $\beta$-glucuronidase (GUS) activity was detected in various rice organs, such as the roots of seedlings, culm, leaf sheaths, leaf blades, and young panicles at the booting stage, except that OsATG8C was also expressed in the panicles at the grain filling stage (Figure 1A). In order to analyze whether the expression of OsATG8c was responsive 
to $\mathrm{N}$ stress, the transcription level of OsATG8c was examined by real-time RT-PCR. The transcriptional level of OsATG8c in rice seedlings was significantly increased under both low $\mathrm{N}(\mathrm{NL})$ and $\mathrm{N}$ deficient (ND) conditions (Figure 1B). The fluorescence signals of YFP-OsATG8c were detected on the cytoplasm and autophagic structures in the tobacco (Nicotiana benthamiana) leaf cells (Figure 1C).

A
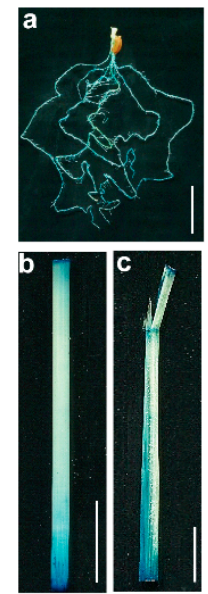
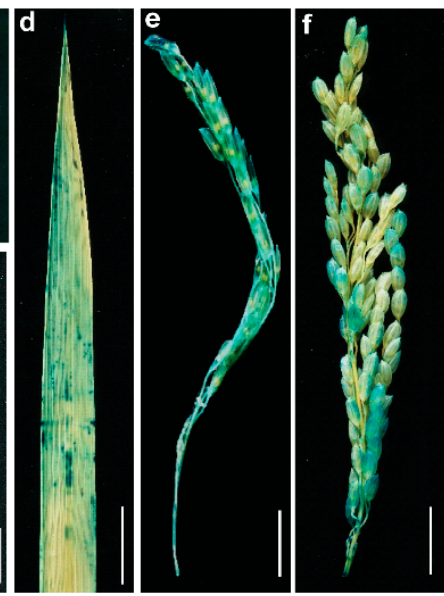

B

C
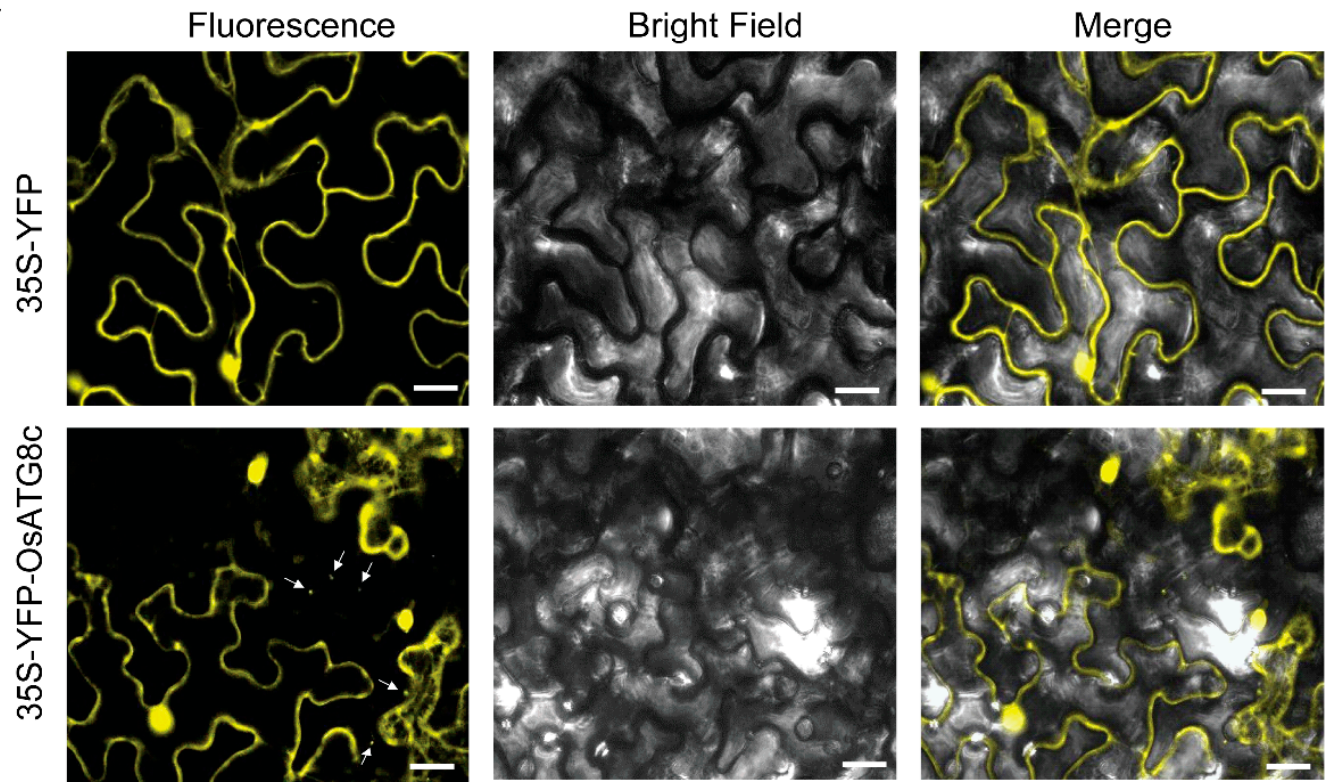

Figure 1. The expression patterns of the OsATG8c gene and protein subcellular localization of OsATG8c. (A) $\beta$-glucuronidase (GUS) histochemical staining of Pro $_{O A A T G 8 c}$-GUS transgenic rice. The tissues used for GUS staining included (a) root, (b) culm, (c) leaf sheath, (d) leaf blade, and panicle at the (e) booting stage and (f) grain filling stage. Scale bars: $2 \mathrm{~cm}$ in a-c and f, $1 \mathrm{~cm}$ in $\mathrm{d}$ and e. (B) The rice seedlings of Shennong9816 (SN9816) were cultured with sufficient nitrogen (N) (NS, $3.5 \mathrm{mM} \mathrm{N}$ ) solution for 14 days and transferred to the same NS (3.5 mM N) solution as the control, low $\mathrm{N}(\mathrm{NL}, 0.8 \mathrm{Mm} \mathrm{N})$ solution and the deficient $\mathrm{N}(\mathrm{ND}, 0 \mathrm{mM} \mathrm{N})$ solution for 1 day and 3 days, respectively. When determining the expression of the OsATG8c gene in leaves, OsActin1 was used as an internal control. Values are means \pm SD $(n=10),{ }^{* *} p<0.01$ ( $t$-test). (C) Subcellular localization of OsATG8c in tobacco leaves. From left to right, the panels show the images of yellow fluorescent protein (YFP) fluorescence and the bright-field and the YFP fluorescence and bright-field overlap image, respectively. 35S-YFP was used as a control. The white arrowheads indicate the autophagic structures. Scale bar: $10 \mu \mathrm{m}$. 


\subsection{Overexpression of OsATG8c Promotes Tillering in Transgenic Rice}

The 35S-OsATG8c fusion construct (Figure S1) was generated, and 17 independent OsATG8coverexpressing transgenic lines were obtained. The transcription level of OsATG8c was confirmed in all transgenic lines using real-time RT-PCR, and 3 homozygous overexpressed lines (L-37, L-42, L-142) were randomly selected for further analysis (Figure 2A). The transcriptional levels of the other OsATGs were not changed in the OsATG8c-overexpressing transgenic rice (Figure S2). Under both normal growth (NS) and N-deficiency (NL) conditions, the transgenic lines showed increased tillering compared with that of the control plant Shennong9816 (SN9816) (Figure 2B-D). In addition, the chlorophyll content (Figure 2E) and protein content (Figure 2F) of the transgenic lines were more than that of the control at the grain filling stage. We further examined the expression levels of some tiller-related genes in rice tiller buds. It was found that the strigolactone pathway genes OsMAX4 and OsD53, the cytokinin oxidase/dehydrogenase (CKX) enzyme coding gene OsCKX2, and the tiller inhibitor OsFC1 were significantly down-regulated in transgenic lines compared with SN9816, whereas the tiller promoting genes OsMOC1 and OsNPF7.2 were significantly up-regulated (Figure 3). Moreover, another two strigolactone pathway genes $(O s D 3$ and $O s D 27)$ as well as three cytokinin degradation genes (OsCKX1, OsCKX3, and OsCKX6) were also down-regulated in transgenic lines (Figure S3). However, the expression level of the tiller inhibiting gene OsSPL14 and two tiller promoting genes (OsIAGLU and OsSta2), as well as the strigolactone pathway genes (OsD14 and OsD17) exhibited no significant differences among SN9816 and the transgenic lines (Figure 3 and Figure S3). In addition, the transgenic lines were shorter than those of the control plants at the jointing stage, and the plant height decreased by up to $15.28 \%$ or $10.53 \%$ compared with that of SN9816 under NS or NL conditions at the grain-filling stage (Figure S4A,B). The decreased plant height in transgenic lines was mainly caused by decreasing the length of the internodes (Figure S4C-E).

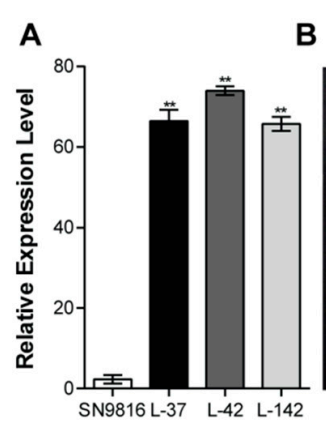

D

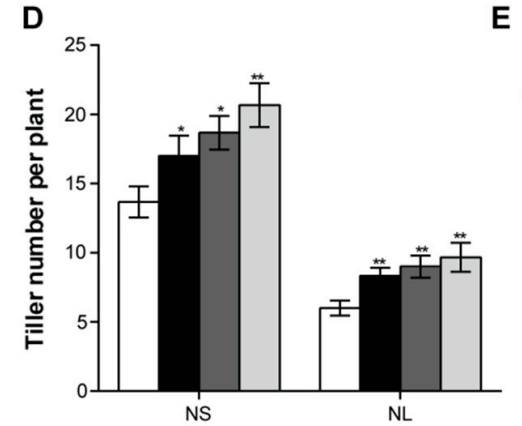

B

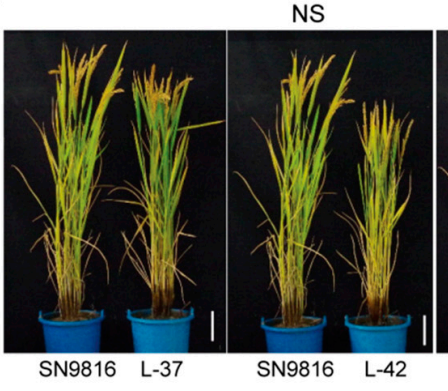

E

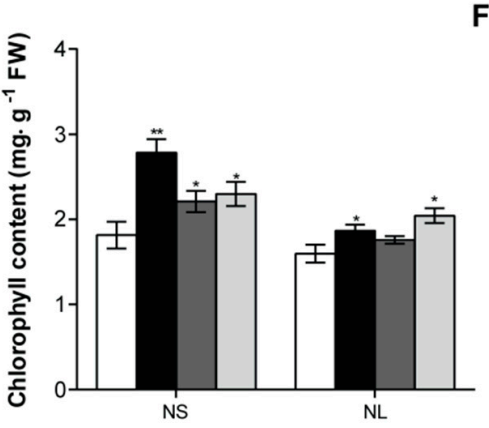

C

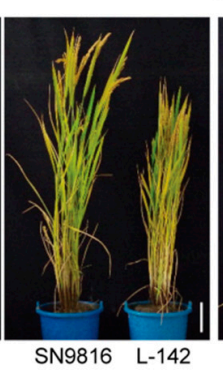

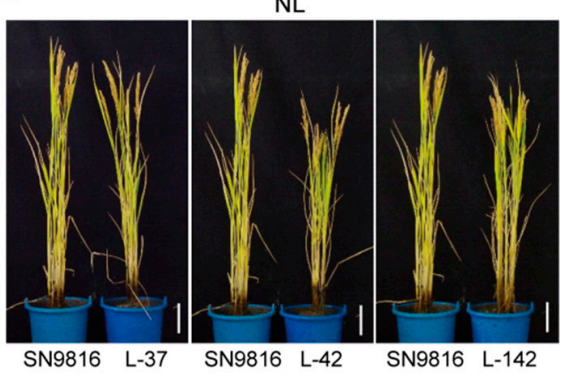

$\mathbf{F}$

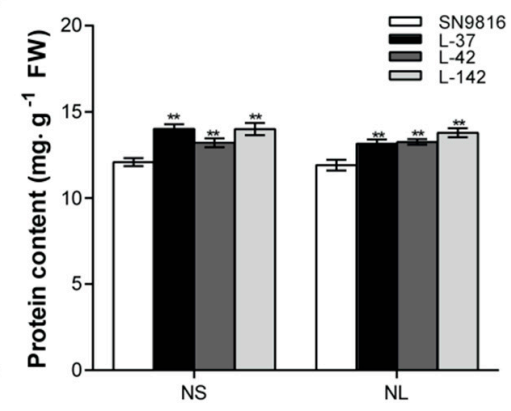

Figure 2. Characterization of 35S-OSATG8C transgenic lines. (A) Expression level of OsATG8c in 14-day-old seedlings of SN9816 and transgenic lines (L-37, L-42 and L-142). OsActin1 was used as an internal control. Values are the means $\pm \mathrm{SD}(n=3)$. (B,C) Phenotypes of the whole rice plants under sufficient $\mathrm{N}\left(\mathrm{NS}, 225 \mathrm{~kg} \cdot \mathrm{ha}^{-1}\right)$ or low $\mathrm{N}\left(\mathrm{NL}, 75 \mathrm{~kg} \cdot \mathrm{ha}^{-1}\right)$ conditions at the grain filling stage. Scale bar: $10 \mathrm{~cm}$. (D) The tiller number per plant, (E) chlorophyll content, and (F) protein content of SN9816 and the transgenic lines under NS $\left(225 \mathrm{~kg} \cdot \mathrm{ha}^{-1}\right)$ and NL $\left(75 \mathrm{~kg} \cdot \mathrm{ha}^{-1}\right)$ conditions. Values are the means \pm SD $(n=12),{ }^{*} p<0.05,{ }^{* *} p<0.01$ (t-test). 

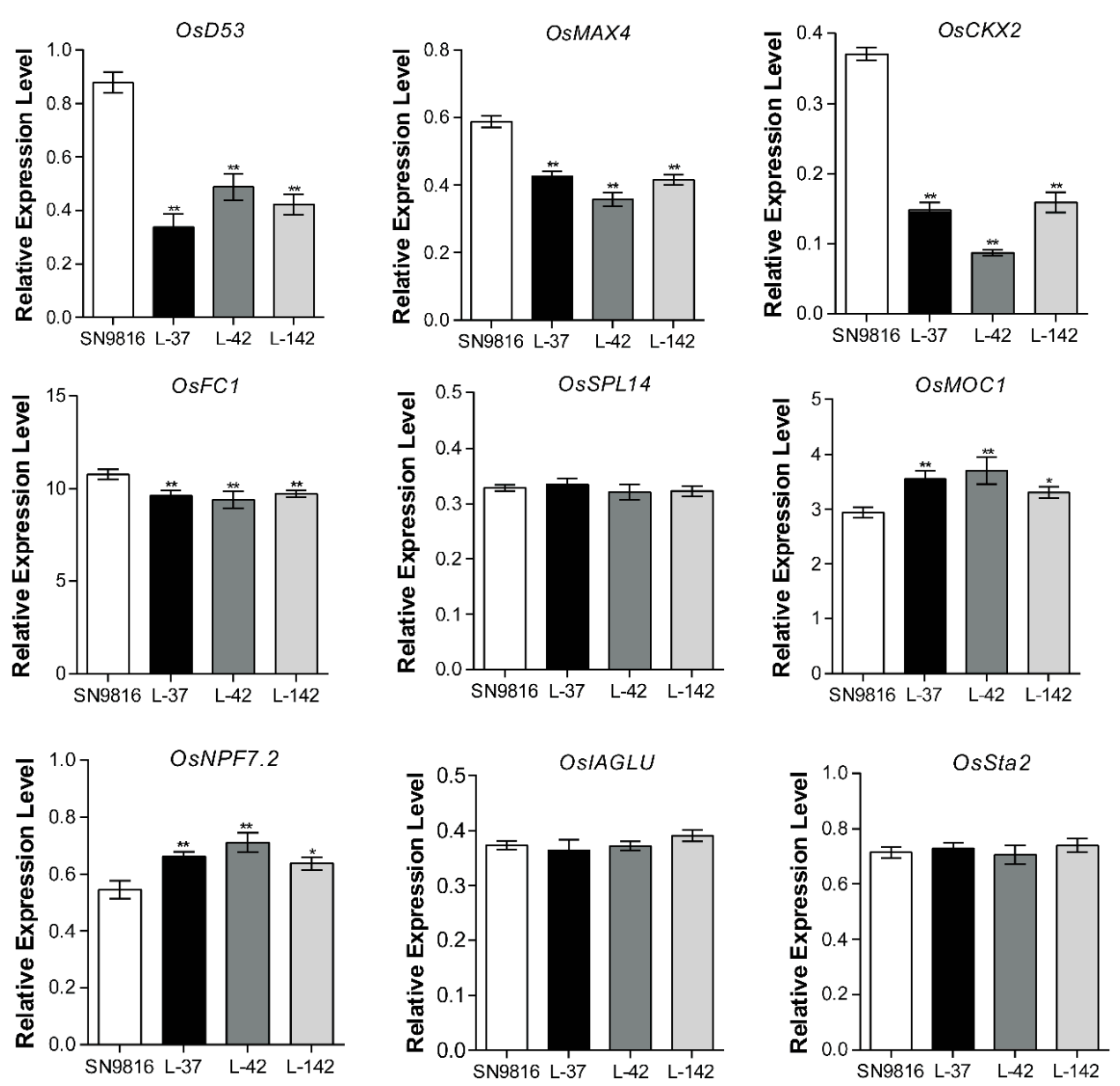

Figure 3. Overexpression of OsATG8c affected the expression of the tiller-related genes. The expression levels of strigolactone pathway genes (OsD53 and OsMAX4), the cytokinin oxidase/dehydrogenase (CKX) enzyme coding gene OsCKX2, tiller inhibiting genes (OsFC1 and OsSPL14), and tiller promoting genes (OsMOC1, OsNPF7.2, OsIAGLU and OsSta2) in the tiller buds of 32-day-old SN9816 and transgenic rice seedlings. Values are the means $\pm \operatorname{SD}(n=10),{ }^{*} p<0.05,{ }^{* *} p<0.01$ (t-test).

\subsection{Overexpression of OsATG8c in Transgenic Rice Enhances the Autophagic Flux}

To investigate whether the autophagic flux was enhanced in the OsATG8c-overexpressing transgenic rice, seedlings of the transgenic lines and control plants were treated with NS solution or ND solution for $24 \mathrm{~h}$. We first examined the number of autophagosomes by monodansylcadaverine (MDC) staining. MDC is an acidophilic dye, which can be used to detect autophagosomes in plants and mammals [54-56]. It was observed that there were significantly more autophagosomes marked by MDC, while the intensity was also higher in the transgenic rice (Figure 4A). The Neighbor of BRCA1 (NBR1) protein is an autophagy receptor, and the substrate degrades in the vacuole of the cell. The degradation level of NBR1 is usually used to identify the selective autophagic flux in plants [57,58]. In addition, the degradation level of NBR1 protein was further investigated by Western blotting. The degradation of the NBR1 protein in transgenic lines increased, especially under $\mathrm{N}$ deficient conditions (Figure 4B, DMSO). Concanamycin A (ConA) was used to inhibit vacuolar acidification and autophagosome turnover. It was observed that ConA-mediated inhibition of vacuolar degradation greatly increased the NBR1 protein level (Figure 4B, +ConA). Previous reports showed that the Arabidopsis autophagy core protein, ATG8a, is an autophagic flux marker protein, as the lipidation of ATG8 can be used to indicate the autophagic activity $[55,59,60]$. The lipidated ATG8 (ATG8-PE) membrane protein was detected by Western blotting to analyze the autophagy flux. It was shown that the overexpression of OsATG8c significantly increased the accumulation of ATG8-PE in the membranes of transgenic lines; 
thus, the lipidation of ATG8 was enhanced, especially under N deficiency conditions and especially with ConA (Figure 4B). All of these results show that the autophagosome number was significantly greater in OsATG8C-overexpressing transgenic lines, and thus, the autophagic flux increased. This increased activity may be the reason for improving the tolerance to $\mathrm{N}$ deficiency stress. In plants, autophagy played an important role in maintaining protein profiles $[15,16]$. The protein content in old leaves (Leaf 1 ) and young leaves (Leaf 3) was compared under both NS and ND conditions. In leaf samples of the same quality, the protein content of old leaves in transgenic lines was lower than that in control plants under both two $\mathrm{N}$ conditions (Figure 4C), and identical leaves under the ND condition had much less protein (Figure 4D). Corresponding to that, the protein content of young leaves in transgenic lines was much higher than that of SN9816 (Figure 4C,D). These results show that the leaf protein content was affected by $\mathrm{N}$ stress and leafage. The autophagy level led to high remobilization and reuse of $\mathrm{N}$ and most proteins from old leaves into young leaves.

A

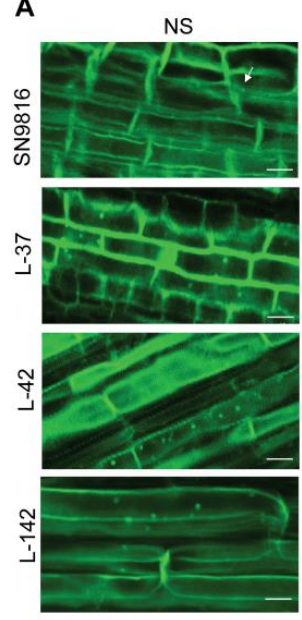

C

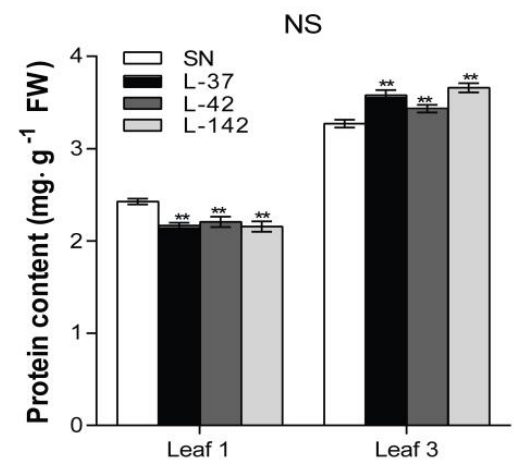

B
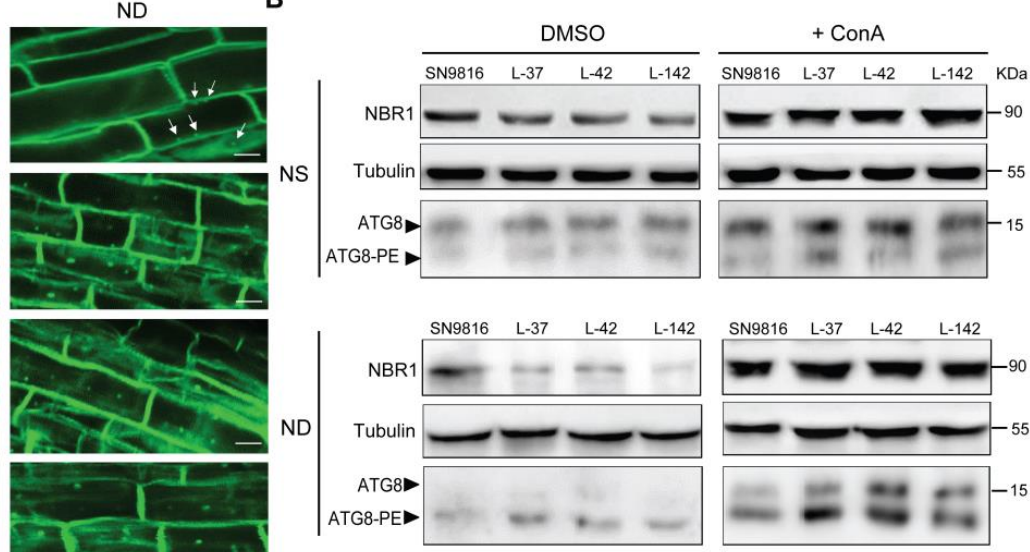

D

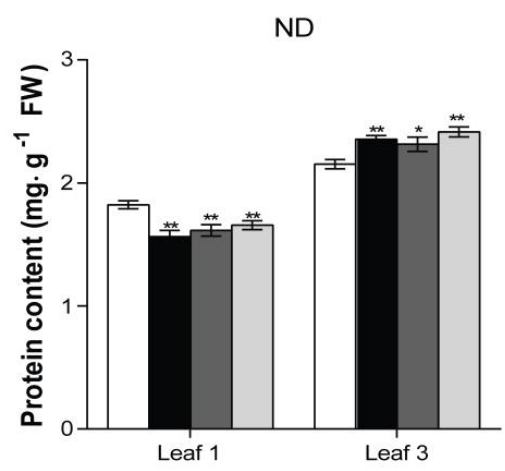

Figure 4. The overexpression of OsATG8c enhanced the autophagy levels and affected leaf protein profiles in rice. The 21-day-old seedlings of SN9816 and overexpressors were transferred to NS $(3.5 \mathrm{mM} \mathrm{N})$ or ND (0 mM N) liquid medium for $24 \mathrm{~h}$. (A) Confocal analysis of autophagosomes in roots by monodansylcadaverine (MDC) staining. MDC-labeled structures are shown in green. The white arrowheads indicate the MDC-stained autophagosomes. Scale bars: $10 \mu \mathrm{m}$. (B) Fourteen-day-old seedlings were transferred to NS $(3.5 \mathrm{mMN})$ and $\mathrm{ND}(0 \mathrm{mM} \mathrm{N})$ liquid media with $0.5 \mu \mathrm{M}$ concanamycin A (ConA) or solvent control DMSO for $24 \mathrm{~h}$. Immunoblot analysis was used to determine the accumulation of NBR1 with anti-NBR1 in Arabidopsis; near-equal protein loads were confirmed with an $\alpha$-tubulin antibody. The membrane fraction was used to detect lipidated (ATG8-PE) and free ATG8 levels with anti-Arabidopsis ATG8a in leaves. (C) The protein content of old leaves (Leaf 1) and (D) young leaves (Leaf 3) in SN9816 and transgenic rice under NS or ND conditions. The protein content in equal weight leaf samples was determined by bicinchoninic acid (BCA) protein assay, which was represented as $\mathrm{mg}$ protein/g fresh weight. Values are the means $\pm \operatorname{SD}(n=3),{ }^{*} p<0.05,{ }^{* *} p<0.01$ ( $t$-test). 


\subsection{Overexpression of OsATG8c Increases the Yield and Promotes NUE in Transgenic Rice}

We further investigated the effect of OsATG8c on the yield and found that the transgenic lines produced significantly more panicles per plant (Figure $5 \mathrm{~A}$ ), and there was little difference in the panicle type compared with that of the control plants under the full $\mathrm{N}$ condition (Figure $5 \mathrm{~B}$ ). However, the grain number per panicle seed setting rate was reduced (Figure 5E,F), while the panicle number per plant significantly increased (Figure 5D). As a result, the transgenic lines had a significantly higher total grain yield per plant than the controls (Figure $5 \mathrm{C}, \mathrm{G}$ ). Corresponding to the higher yield in transgenic lines, the biomass also increased up to $25.72 \%$ and $19.49 \%$ under NS and NL conditions, respectively (Figure 5H). Since the biomass significantly increased in the OsATG8c-overexpressing transgenic lines, both the NUpE and NUE were higher under both NS and NL conditions (Figure 5I,J), suggesting that OsATG8c might be essential for both grain yield and NUE.

A

A
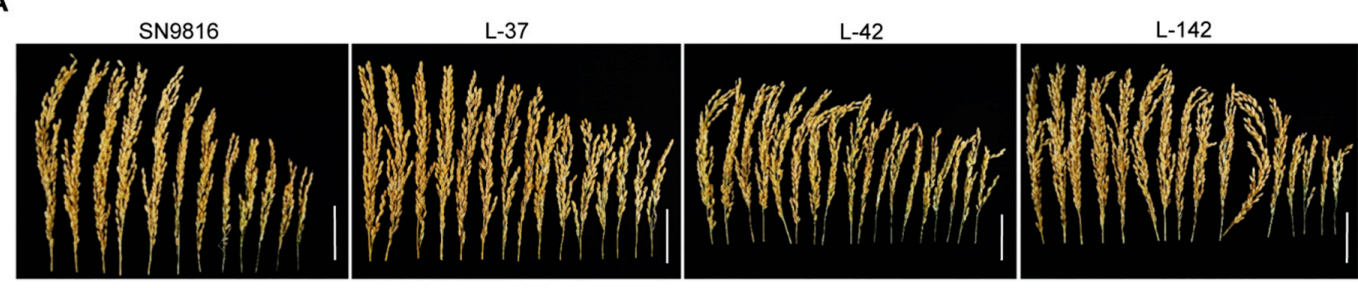

B

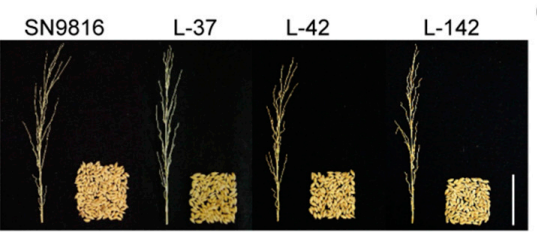

C SN9816

$L-42$

$\mathrm{L}-142$

D

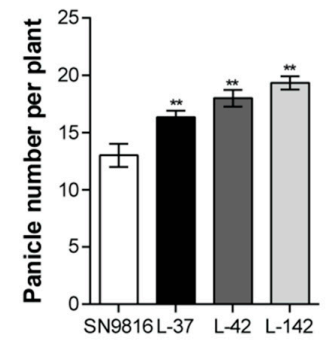

H

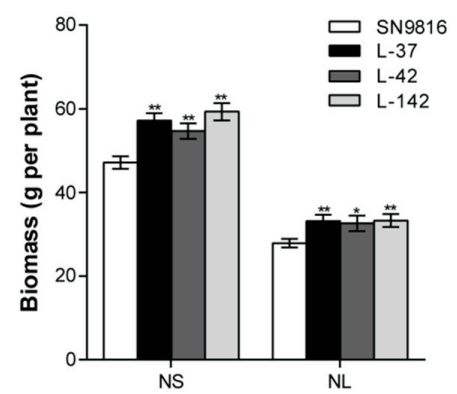

E

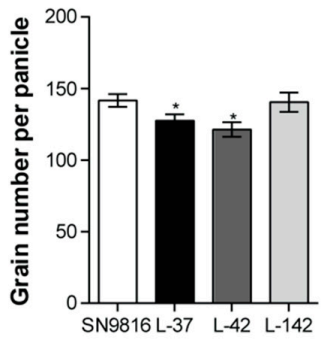

I

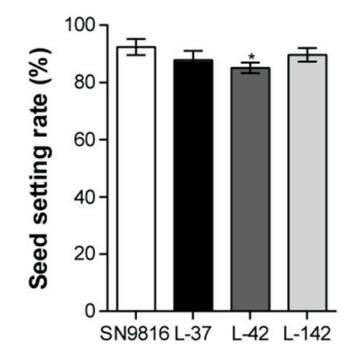

G

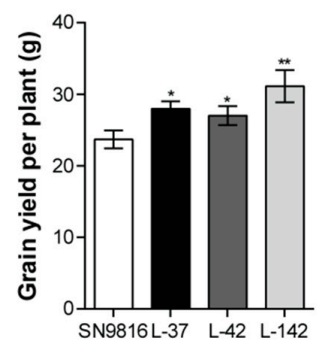

J
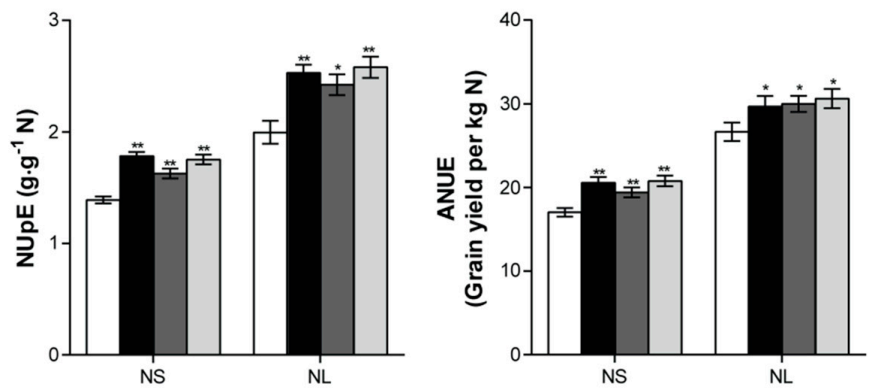

Figure 5. (A) The panicles per plant, (B) grains per panicle, (C) total grains per plant, (D) panicle number per plant, (E) grain number per panicle, $(F)$ seed setting rate, and (G) grain yield per plant of SN9816 and OsATG8c-overexpressing transgenic rice grown under NS (225 kg.ha $\left.{ }^{-1}\right)$ conditions. Scale bar: $5 \mathrm{~cm}$. Biomass per plant (dry weight of all aboveground) $(\mathbf{H})$, nitrogen uptake efficiency $(\mathrm{NUpE})(\mathbf{I})$, and nitrogen use efficiency (NUE) (J) of SN9816 and OsATG8c-overexpressing lines grown under NS $\left(225 \mathrm{~kg} \cdot \mathrm{ha}^{-1}\right)$ and NL $\left(75 \mathrm{~kg} \cdot \mathrm{ha}^{-1}\right)$ conditions. Values are the means $\pm \operatorname{SD}(n=12),{ }^{*} p<0.05$, ** $p<0.01$ (t-test). 


\section{Discussion}

Autophagy takes part in the nutritional cycle of all eukaryotes and also acts as a pivotal part in the remobilization and transfer of $\mathrm{N}$ from old leaves to grains in plants [61]. Previous studies have also shown that many ATG genes are transcriptionally up-regulated under nutrient-deficient conditions, and enhanced autophagy also occurs $[46,47,62-64]$. In this study, the core gene of autophagy in rice, OsATG8c, was preferentially expressed after three days of $\mathrm{N}$ starvation (both ammonium and nitrate starvation or even free) (Figure 1B), indicating that OsATG8c may also confer tolerance to this stress in rice. However, earlier studies also investigated the expression pattern of OsATG8C subjected to ammonium or nitrate starvation and, except for a slight reduction after $24 \mathrm{~h}$ of ammonium starvation, there were no obvious expression changes [46]. The differences shown in our results might be due to the different experimental processing conditions and degree of nitrogen starvation used. Xia et al. performed semi-quantitative RT-PCRs to detect the OsATG8c expression profile in rice at the booting and the seedling stage [46]. Furthermore, we reported the temporal and spatial profiles of the expression of OsATG8c by histochemical staining (Figure 1A), and the result was supplementary to the previous results.

Here, we further demonstrated the effect of OsATG8c on rice growth and yield. It was found that the overexpressed OsATG8c could not only promote the growth of rice but also restore growth inhibition due to nitrogen deficiency in the transgenic rice (Figure 2C). As the transcriptional levels of other OsATGs were not affected in the OsATG8c-overexpressing rice (Figure S2), we considered that the phenotypes of the transgenic lines were determined by OsATG8c-mediated increased autophagy. The 35S-OsATG8c transgenic lines not only grew better than SN9816 under N-limited conditions, but they also performed better under normal growth conditions. The transgenic rice plants overexpressing OsATG8c had increased chlorophyll and protein contents in the leaves (Figure 2E,F), as well as greater biomass accumulation (Figure $5 \mathrm{H}$ ). During the vegetative growth stage, the transgenic lines showed greater accumulation of the photosynthetic products, and this would be more $\mathrm{N}$ for plants to use in reproductive growth and yield.

Interestingly, after statistical analysis, it was found that the plant height of the OsATG8coverexpressing rice decreased (Figure S4). In agronomy, plant height becomes shorter, which is a good characteristic for production and is considered the ideal plant type. Furthermore, the overexpression of OsATG8c significantly promoted effective rice tillering and increased yield (Figure 5A,C). Although the grain number per panicle reduced in the OsATG8c-overexpressing lines (Figure 5E), the panicle number per plant was more than that of the control, so the yield still increased (Figure 5D,G). It has been reported that OsMOC1 and OsNPF7.2 promote rice tillering [25,38], while OsFC1 inhibits tillering [26]. In the OsATG8c-overexpressing transgenic rice, the expression levels of OsMOC1 and OsNPF7.2 were increased, but the expression of OsFC1 was decreased (Figure 3), which finally resulted in an increased tillers number. Besides, the biosynthesis and signaling related genes of strigolactones and cytokinin oxidase/dehydrogenase ( $\mathrm{CKX})$ enzyme coding gene OsCKX2 were reported to be involved in the tillering regulation in rice [32,33,35]. In this study, the overexpression of OsATG8c down-regulated the strigolactone synthesis genes (OsMAX4, OsD27) and signaling genes (OsD3, OsD53), as well as the cytokinin degradation genes OsCKXs in transgenic lines (Figure 3 and Figure S3), which suggests that the cytokinin and strigolactone pathways might be involved in the function of OsATG8c in promoting rice tillering. As rice tillering is an important determinant of the panicle number and grain yield [22], the increased tiller and panicle number in the 35S-OsATG8c transgenic rice resulted in an increase in yield. Meanwhile, GUS histochemical staining showed that OsATG8C was expressed in the developing panicles (Figure 1A), suggesting that the OsATG8c gene may also be involved in grain formation in rice.

Studies on some atg deletion mutants of Arabidopsis, maize, and rice have shown diminished growth and development, accelerated senescence, a decreased number of autophagosomes, and decreased autophagy activity, as well as decreased $\mathrm{N}$ remobilization from leaves to seeds $[9,11,13,15,65]$. As shown in Figure 4A,B, the increased autophagosomes in transgenic rice and the enhanced ATG8a lipidation in OsATG8c-overexpressing lines, particularly under $\mathrm{N}$ deficiency condition, as well as 
the accumulation of NBR1 with/without ConA, all suggest that autophagic flux was significantly stimulated in transgenic rice. In addition, since the degradation of protein occurred in response to leaf senescence, it was also detected that the degradation of proteins during leaf senescence was enhanced in the transgenic rice, confirming that the autophagy level was raised in another aspect (Figure 4C,D). As a result, the autophagy activity was significantly promoted in OsATG8c-overexpressing transgenic rice, thereby increasing the tolerance to $\mathrm{N}$ stress. On the other hand, the advanced autophagy activity phenotype extended the remobilization of nutrients, resulting in an increased number of panicles and, consequently, a better yield (Figure 5A,C,G). Autophagy is a facilitator of nutrient remobilization in plants, and it also plays a vital role in improving the NUE and crop yield protection [66]. The redundant $\mathrm{N}$ in the cells cannot be effectively recovered or utilized, leading to nutrient accumulation and wastage, cell death, and a lower amino acid content, all of which suppress the growth and reduce the NUE of plants with defective autophagy [67]. Our contemporaneous research showed that the overexpressed OsATG8a in transgenic rice not only increased the autophagic flux, but also had a significant phenotypic change on vegetative growth and fecundity [53]. Although OsATG8a and OsATG8C belong to a subfamily in rice, their phylogenetic distance was large, indicating that the divergence of these two genes might have occurred very early, so we speculated that their functions may be different. Overexpression of OsATG8a significantly increased NUE and NUpE under normal N conditions, but did not seem to have any effect on NUE under suboptimal N conditions. Interestingly, it was shown that the NUpE and NUE of transgenic rice were higher under the two $\mathrm{N}$ conditions. In addition, overexpression of OsATG8a in rice might promote the remobilization of proteins from leaves into seeds. While, overexpression of OsATG8c could promote the remobilization and reuse of proteins from old leaves to young leaves. The increased grain yield was at least partially caused by effective remobilization of assimilated $\mathrm{N}$ from the vegetative tissue to the developing seeds, presumably due to enhanced $\mathrm{N}$ uptake and $\mathrm{N}$ recycling by autophagy. Although the NUpE and NUE of transgenic rice were both increased under the two $\mathrm{N}$ conditions, we did not observe an increased yield under the $\mathrm{N}$ deficiency condition. A possible reason for this might be due the harsh $\mathrm{N}$ deficiency condition. The low nitrogen condition (NL) that we used in this research was a two-thirds $\mathrm{N}$ deficiency condition containing only a one-third of the N supply compared to that of the NS treatment, which was already a very harsh condition. The limited $\mathrm{N}$ might have contributed to the maintenance of normal plant growth and enhanced the resistance to $\mathrm{N}$ stress. Since autophagic recycling is required for nutrient mobilization, the yield increment observed in the transgenic lines could be a benefit of the enhanced autophagic recycling ability, leading to efficient $\mathrm{N}$ cycling, as nutrients are remobilized from the leaves to the reproductive organs (grains). Even under a very harsh $\mathrm{N}$ deficiency (NL) condition, compared with the control rice, transgenic rice still had enhanced NUpE and NUE. This indicates that the $O s A T G 8 c$ gene has great potential to be of benefit in agricultural production.

\section{Materials and Methods}

\subsection{Plant Materials and Growth Conditions}

The japonica (Oryza sativa) cultivar Shennong9816 (SN9816), the main variety of Shenyang in northeast China, was used as control plant. Rice seedlings were grown hydroponically in a growth chamber $\left(28^{\circ} \mathrm{C} / 25^{\circ} \mathrm{C}\right.$ and $10 \mathrm{~h}$ light $/ 14 \mathrm{~h}$ dark $)$, with modified half Hoagland's solution containing different $\mathrm{N}$ concentrations ( $\mathrm{pH}=5.7$ ) as previously described [51] for short-term treatment.

\subsection{Binary Vector Construction}

To produce the 35S-OsATG8c and 35S-YFP-OsATG8c fusion constructs, the OsATG8c complete coding region was amplified and cloned into the binary vectors pCAMBIA1301 and pCAMBIA1300-YFP. A 1405-bp promoter fragment of the OsATG8c was amplified and cloned into pCAMBIA1301 vector to construct the Pro ${ }_{O S A T G 8 c}$-GUS fusion gene. The corresponding primers are listed in Table $\mathrm{S} 1$ and all the fusion constructs were confirmed by sequencing. 


\subsection{Gene Expression Analysis}

To analyze OsATG8c expression responsive to $\mathrm{N}$ stress in rice, rice seedlings were grown for 14 days in half Hoagland's solution (NS, $3.5 \mathrm{mM} \mathrm{N}$ ), then supplied with the same NS solution as the control, low $\mathrm{N}\left(\mathrm{NL}, 0.8 \mathrm{mM} \mathrm{N}\right.$ ) solution (with $0.6 \mathrm{mM} \mathrm{KNO}_{3}$ and $0.1 \mathrm{mM}\left(\mathrm{NH}_{4}\right)_{2} \mathrm{SO}_{4}, \mathrm{pH}=5.7$ ) and the $\mathrm{N}$-free $\left(\mathrm{ND}, 0 \mathrm{mM} \mathrm{N}\right.$ ) solution, $\mathrm{KCl}$ was used to supplement the lack of $\mathrm{K}^{+}$. The 21-day-old seedlings of SN9816 and 35S-OsATG8c transgenic lines cultured with NS solution were sampled for expression analysis of the other OsATGs. To analyze the expression level of tiller related genes, tiller buds were obtained from the 32-day-old rice seedlings of SN9816 and 35S-OsATG8c transgenic lines. Total RNA extraction, cDNA synthesized and real-time RT-PCR were conducted as previously described [53]. OsActin1 was used as an internal control. The corresponding primers used for gene expression analysis are listed in Table S1. All experiments were subjected to 3 biological replicates.

4.4. Protein Isolation and Immunoblot Analysis, Rice Transformation, MDC Staining, Measurement of Chlorophyll, Soluble Protein Content, and Analysis of Agronomic Traits, Biomass, NUpE and

NUE Calculations

All of these were performed as described previously [53].

\subsection{Field Trials of Rice}

35S-OsATG8c transgenic rice ( $\mathrm{T}_{3}$ generation) and SN9816 were grown under natural growth condition at Shenyang Agricultural University experimental farm (Shenyang, China; Longitude: $123.34^{\circ} \mathrm{E}$ Latitude: $41.49^{\circ} \mathrm{N}$ ). Field trials for $\mathrm{N}$ fertilizer treatments were conducted as described previously [53].

\subsection{GUS Histochemical Staining}

Pro $_{O A A T G 8 c}$-GUS transgenic rice was used to analyze the temporal and spatial expression patterns. GUS histochemical staining was performed as described in [68], in tissues from the root, culm, leaf sheath, leaf blade, and panicle of Pro $_{O s A T G 8 c}$-GUS transgenic rice.

\subsection{Subcellular Localization Assay}

The subcellular localization analysis of OsATG8c was conducted with the 35S-YFP-OsATG8c fusion constructs. The sequence-verified construction was introduced into the Agrobacterium strain GV3101 and then used to infiltrate tobacco leaves according to published methods [69]. The YFP fluorescence was observed by confocal microscopy (Zeiss LSM 780, Carl Zeiss, Jena, Germany).

\subsection{Statistical Analysis}

Data comparisons between transgenic lines and SN9816 were statistically analyzed by Student's $t$-test at significance levels of $* p<0.05$ and ${ }^{* *} p<0.01$.

Supplementary Materials: The following are available online at http://www.mdpi.com/1422-0067/20/19/4956/s1.

Author Contributions: F.X. designed the study and wrote the paper. X.Z. constructed the transgenic lines, performed Western blot analysis, gene expression analysis, subcellular localization assay and NUE calculations. X.L. performed the phenotypic analysis, GUS staining, measurement of chlorophyll, soluble protein, and agronomic traits. J.Y. performed the total RNA extraction and MDC staining. X.Z. analyzed the results and prepared the figures and tables. All authors discussed the results and commented on the manuscript. All authors have read and approved the final manuscript.

Funding: This work was supported by grants from the National Natural Science Foundation of China (grant number 31401298), the National Key Research and Development Program of China (grant number 2018YFD0200200), and the Liao Ning Revitalization Talents Program (grant number XLYC1808003).

Conflicts of Interest: The authors declare no conflict of interest. 


\section{Abbreviations}

$\begin{array}{ll}\text { ATG } & \text { Autophagy } \\ \text { NUE } & \text { Nitrogen use efficiency } \\ \text { NUpE } & \text { Nitrogen uptake efficiency } \\ \text { MDC } & \text { Monodansylcadaverine } \\ \text { ConA } & \text { Concanamycin A }\end{array}$

\section{References}

1. Yang, X.; Bassham, D.C. New insight into the mechanism and function of autophagy in plant cells. Int. Rev. Cell Mol. Biol. 2015, 320, 1-40. [PubMed]

2. Tsukada, M.; Ohsumi, Y. Isolation and characterization of autophagy-defective mutants of Saccharomyces cerevisiae. FEBS Lett. 1993, 333, 169-174. [CrossRef]

3. Feng, Y.; He, D.; Yao, Z.; Klionsky, D.J. The machinery of macroautophagy. Cell Res. 2014, $24,24-41$. [CrossRef]

4. Ohsumi, Y. Molecular dissection of autophagy: Two ubiquitin-like systems. Nat. Rev. Mol. Cell Biol. 2001, 2, 211-216. [CrossRef] [PubMed]

5. Yao, Z.; Delormeaxford, E.; Backues, S.K.; Klionsky, D.J. Atg41/Icy2 regulates autophagosome formation. Autophagy 2015, 11, 2288-2299. [CrossRef]

6. Doelling, J.H.; Walker, J.M.; Friedman, E.M.; Thompson, A.R.; Vierstra, R.D. The APG8/12-activating enzyme APG7 is required for proper nutrient recycling and senescence in Arabidopsis thaliana. J. Biol. Chem. 2002, 277, 33105-33114. [CrossRef] [PubMed]

7. Rose, T.L.; Bonneau, L.; Der, C.; Martymazars, D.; Marty, F. Starvation-induced expression of autophagy-related genes in Arabidopsis. Biol. Cell 2006, 98, 53-67. [CrossRef] [PubMed]

8. Thomas, H. Senescence, ageing and death of the whole plant. New Phytol. 2012, 197, 696-711. [CrossRef]

9. Liu, Y.; Bassham, D.C. Autophagy: Pathways for self-eating in plant cells. Annu. Rev. Plant Biol. 2012, 63, 215-237. [CrossRef]

10. Guiboileau, A.; Yoshimoto, K.; Soulay, F.; Bataille, M.P.; Avice, J.C.; Masclaux-Daubresse, C. Autophagy machinery controls nitrogen remobilization at the whole-plant level under both limiting and ample nitrate conditions in Arabidopsis. New Phytol. 2012, 194, 732-740. [CrossRef]

11. Guiboileau, A.; Avila-Ospina, L.; Yoshimoto, K.; Soulay, F.; Azzopardi, M.; Marmagne, A.; Lothier, J.; Masclaux-Daubresse, C. Physiological and metabolic consequences of autophagy deficiency for the management of nitrogen and protein resources in Arabidopsis leaves depending on nitrate availability. New Phytol. 2013, 199, 683-694. [CrossRef] [PubMed]

12. Berardino, J.D.; Marmagne, A.; Berger, A.; Yoshimoto, K.; Cueff, G.; Chardon, F.; Masclaux-Daubresse, C.; Reisdorf-Cren, M. Autophagy controls resource allocation and protein storage accumulation in Arabidopsis seeds. J. Exp. Bot. 2018, 69, 1403-1414. [CrossRef] [PubMed]

13. Wada, S.; Hayashida, Y.; Izumi, M.; Kurusu, T.; Hanamata, S.; Kanno, K.; Kojima, S.; Yamaya, T.; Kuchitsu, K.; Makino, A.; et al. Autophagy supports biomass production and nitrogen use efficiency at the vegetative stage in rice. Plant Physiol. 2015, 168, 60-73. [CrossRef] [PubMed]

14. Kurusu, T.; Koyano, T.; Kitahata, N.; Kojima, M.; Hanamata, S.; Sakakibara, H.; Kuchitsu, K. Autophagymediated regulation of phytohormone metabolism during rice anther development. Plant Signal. Behav. 2017, 12, e1365211. [CrossRef] [PubMed]

15. Li, F.; Chung, T.; Pennington, J.G.; Federico, M.L.; Kaeppler, H.F.; Kaeppler, S.M.; Otegui, M.S.; Vierstra, R.D. Autophagic recycling plays a central role in maize nitrogen remobilization. Plant Cell 2015, 27, 1389-1408. [CrossRef]

16. McLoughlin, F.; Augustine, R.C.; Marshall, R.S.; Li, F.; Kirkpatrick, L.D.; Otegui, M.S.; Vierstra, R.D. Maize multi-omics reveal roles for autophagic recycling in proteome remodelling and lipid turnover. Nat. Plants 2018, 4, 1056-1070. [CrossRef] [PubMed]

17. Avila-Ospina, L.; Moison, M.; Yoshimoto, K.; Masclaux-Daubresse, C. Autophagy, plant senescence, and nutrient recycling. J. Exp. Bot. 2014, 65, 3799-3811. [CrossRef]

18. Krapp, A. Plant nitrogen assimilation and its regulation: A complex puzzle with missing pieces. Curr. Opin. Plant Biol. 2015, 25, 115-122. [CrossRef] 
19. Kraiser, T.; Gras, D.E.; Gutierrez, A.G.; Gonzalez, B.; Gutierrez, R.A. A holistic view of nitrogen acquisition in plants. J. Exp. Bot. 2011, 62, 1455-1466. [CrossRef]

20. Chardon, F.; Noël, V.; Masclauxdaubresse, C. Exploring NUE in crops and in Arabidopsis ideotypes to improve yield and seed quality. J. Exp. Bot. 2012, 63, 3401-3412. [CrossRef]

21. Kichey, T.; Hirel, B.; Heumez, E.; Dubois, F.; Gouis, J.L. In winter wheat (Triticum aestivum L.), post-anthesis nitrogen uptake and remobilisation to the grain correlates with agronomic traits and nitrogen physiological markers. Field Crop. Res. 2007, 102, 22-32. [CrossRef]

22. Xing, Y.; Zhang, Q. Genetic and molecular bases of rice yield. Annu. Rev. Plant Biol. 2010, 61, 421-442. [CrossRef] [PubMed]

23. Wang, Y.; Li, J. Branching in rice. Curr. Opin. Plant Biol. 2011, 14, 94-99. [CrossRef] [PubMed]

24. Domagalska, M.A.; Leyser, O. Signal integration in the control of shoot branching. Nat. Rev. Mol. Cell Biol. 2011, 12, 211-221. [CrossRef] [PubMed]

25. Li, X.; Qian, Q.; Fu, Z.; Wang, Y.; Xiong, G.; Zeng, D.; Wang, X.; Liu, X.; Teng, S.; Hiroshi, F.; et al. Control of tillering in rice. Nature 2003, 422, 618-621. [CrossRef] [PubMed]

26. Takeda, T.; Suwa, Y.; Suzuki, M.; Kitano, H.; Ueguchi-Tanaka, M.; Ashikari, M.; Matsuoka, M.; Ueguchi, C. The OsTB1 gene negatively regulates lateral branching in rice. Plant J. 2003, 33, 513-520. [CrossRef]

27. Jiao, Y.; Wang, Y.; Xue, D.; Wang, J.; Yan, M.; Liu, G.; Dong, G.; Zeng, D.; Lu, Z.; Zhu, X.; et al. Regulation of OsSPL14 by OsmiR156 defines ideal plant architecture in rice. Nat. Genet. 2010, 42, 541-544. [CrossRef] [PubMed]

28. Ishikawa, S.; Maekawa, M.; Arite, T.; Onishi, K.; Takamure, I.; Kyozuka, J. Suppression of tiller bud activity in tillering dwarf mutants of rice. Plant Cell Physiol. 2005, 46, 79-86. [CrossRef]

29. Zou, J.; Zhang, S.; Zhang, W.; Li, G.; Chen, Z.; Zhai, W.; Zhao, X.; Pan, X.; Xie, Q.; Zhu, L. The rice HIGH-TILLERING DWARF1 encoding an ortholog of Arabidopsis MAX3 is required for negative regulation of the outgrowth of axillary buds. Plant J. 2006, 48, 687-698. [CrossRef] [PubMed]

30. Arite, T.; Iwata, H.; Ohshima, K.; Maekawa, M.; Nakajima, M.; Kojima, M.; Sakakibara, H.; Kyozuka, J. DWARF10, an RMS1/MAX4/DAD1 ortholog, controls lateral bud outgrowth in rice. Plant J. 2007, 51, 1019-1029. [CrossRef]

31. Arite, T.; Umehara, M.; Ishikawa, S.; Hanada, A.; Maekawa, M.; Yamaguchi, S.; Kyozuka, J. d14, a strigolactone-insensitive mutant of rice, shows an accelerated outgrowth of tillers. Plant Cell Physiol. 2009, 50, 1416-1424. [CrossRef] [PubMed]

32. Lin, H.; Wang, R.; Qian, Q.; Yan, M.; Meng, X.; Fu, Z.; Yan, C.; Jiang, B.; Su, Z.; Li, J.; et al. DWARF27, an iron-containing protein required for the biosynthesis of strigolactones, regulates rice tiller bud outgrowth. Plant Cell 2009, 21, 1512-1525. [CrossRef] [PubMed]

33. Jiang, L.; Liu, X.; Xiong, G.; Liu, H.; Chen, F.; Wang, L.; Meng, X.; Liu, G.; Yu, H.; Yuan, Y.; et al. DWARF 53 acts as a repressor of strigolactone signalling in rice. Nature 2013, 504, 401-405. [CrossRef] [PubMed]

34. Ashikari, M.; Sakakibara, H.; Lin, S.; Yamamoto, T.; Takashi, T.; Nishimura, A.; Angeles, E.R.; Qian, Q.; Kitano, H.; Matsuoka, M. Cytokinin oxidase regulates rice grain production. Science 2005, 309, 741-745. [CrossRef] [PubMed]

35. Yeh, S.Y.; Chen, H.W.; Ng, C.Y.; Lin, C.Y.; Tseng, T.H.; Li, W.H.; Ku, M.S. Down-regulation of cytokinin oxidase 2 expression increases tiller number and improves rice yield. Rice 2015, 8, 36. [CrossRef]

36. Choi, M.-S.; Koh, E.-B.; Woo, M.-O.; Piao, R.; Oh, C.-S.; Koh, H.-J. Tiller formation in rice is altered by overexpression of OsIAGLU gene encoding an IAA-conjugating enzyme or exogenous treatment of free IAA. J. Plant Biol. 2013, 55, 429-435. [CrossRef]

37. Kumar, M.; Choi, J.; An, G.; Kim, S.R. Ectopic Expression of OsSta2 Enhances Salt Stress Tolerance in Rice. Front. Plant Sci. 2017, 8, 316. [CrossRef]

38. Wang, J.; Lu, K.; Nie, H.; Zeng, Q.; Wu, B.; Qian, J.; Fang, Z. Rice nitrate transporter OsNPF7.2 positively regulates tiller number and grain yield. Rice 2018, 11, 12. [CrossRef]

39. Lu, K.; Wu, B.; Wang, J.; Zhu, W.; Nie, H.; Qian, J.; Huang, W.; Fang, Z. Blocking amino acid transporter OsAAP3 improves grain yield by promoting outgrowth buds and increasing tiller number in rice. Plant Biotechnol. J. 2018, 16, 1710-1722. [CrossRef]

40. Nakatogawa, H.; Ichimura, Y.; Ohsumi, Y. Atg8, a ubiquitin-like protein required for autophagosome formation, mediates membrane tethering and hemifusion. Cell 2007, 130, 165-178. [CrossRef] 
41. Xie, Z.; Nair, U.; Klionsky, D.J. An InCytes from MBC selection: Atg8 controls phagophore expansion during autophagosome formation. Mol. Biol. Cell 2008, 19, 3290-3298. [CrossRef] [PubMed]

42. Avin-Wittenberg, T.; Honig, A.; Galili, G. Variations on a theme: Plant autophagy in comparison to yeast and mammals. Protoplasma 2012, 249, 285-299. [CrossRef] [PubMed]

43. Ichimura, Y.; Kirisako, T.; Takao, T.; Satomi, Y.; Shimonishi, Y.; Ishihara, N.; Mizushima, N.; Tanida, I.; Kominami, E.; Ohsumi, M. A ubiquitin-like system mediates protein lipidation. Nature 2000, 408, 488-492. [CrossRef] [PubMed]

44. Su, W.; Ma, H.; Liu, C.; Wu, J.; Yang, J. Identification and characterization of two rice autophagy associated genes, OsAtg8 and OsAtg4. Mol. Biol. Rep. 2006, 33, 273-278. [CrossRef] [PubMed]

45. Chung, T.; Suttangkakul, A.; Vierstra, R.D. The ATG autophagic conjugation system in maize: ATG transcripts and abundance of the ATG8-lipid adduct are regulated by development and nutrient availability. Plant Physiol. 2009, 149, 220-234. [CrossRef] [PubMed]

46. Xia, K.; Liu, T.; Ouyang, J.; Wang, R.; Fan, T.; Zhang, M. Genome-wide identification, classification, and expression analysis of autophagy-associated gene homologues in rice (Oryza sativa L.). DNA Res. 2011, 18, 363-377. [CrossRef] [PubMed]

47. Li, W.; Chen, M.; Wang, E.; Hu, L.; Hawkesford, M.J.; Zhong, L.; Chen, Z.; Xu, Z.; Li, L.; Zhou, Y. Genome-wide analysis of autophagy-associated genes in foxtail millet (Setaria italica L.) and characterization of the function of SiATG8a in conferring tolerance to nitrogen starvation in rice. BMC Genom. 2016, 17, 797. [CrossRef]

48. Li, W.; Chen, M.; Zhong, L.; Liu, J.; Xu, Z.; Li, L.C.; Zhou, Y.; Guo, C.; Ma, Y. Overexpression of the autophagy-related gene SiATG8a from foxtail millet (Setaria italica L.) confers tolerance to both nitrogen starvation and drought stress in Arabidopsis. Biochem. Biophys. Res. Commun. 2015, 468, 800-806. [CrossRef]

49. Slavikova, S.; Ufaz, S.; Avinwittenberg, T.; Levanony, H.; Galili, G. An autophagy-associated Atg8 protein is involved in the responses of Arabidopsis seedlings to hormonal controls and abiotic stresses. J. Exp. Bot. 2008, 59, 4029-4043. [CrossRef]

50. Wang, P.; Sun, X.; Jia, X.; Wang, N.; Gong, X.; Ma, F. Characterization of an autophagy-related gene MdATG8i from apple. Front. Plant Sci. 2016, 7, 720. [CrossRef]

51. Xia, T.; Xiao, D.; Liu, D.; Chai, W.; Gong, Q.; Wang, N. Heterologous expression of ATG8c from soybean confers tolerance to nitrogen deficiency and increases yield in Arabidopsis. PLoS ONE 2012, 7, e37217. [CrossRef] [PubMed]

52. Chen, Q.; Soulay, F.; Saudemont, B.; Elmayan, T.; Marmagne, A.; Masclaux-Daubresse, C. Overexpression of ATG8 in Arabidopsis stimulates autophagic activity and increases nitrogen remobilization efficiency and grain filling. Plant Cell Physiol. 2018, 60, 343-352. [CrossRef] [PubMed]

53. Yu, J.; Zhen, X.; Li, X.; Li, N.; Xu, F. Increased autophagy of rice can increase yield and nitrogen use efficiency (NUE). Front. Plant Sci. 2019, 10, 584. [CrossRef] [PubMed]

54. Biederbick, A.; Kern, H.F.; Elsässer, H. Monodansylcadaverine (MDC) is a specific in vivo marker for autophagic vacuoles. Eur. J. Cell Biol. 1995, 66, 3-14. [PubMed]

55. Contento, A.L.; Xiong, Y.; Bassham, D.C. Visualization of autophagy in Arabidopsis using the fluorescent dye monodansylcadaverine and a GFP-AtATG8e fusion protein. Plant J. 2005, 42, 598-608. [CrossRef] [PubMed]

56. Qi, H.; Xia, F.N.; Xie, L.J.; Yu, L.J.; Chen, Q.F.; Zhuang, X.H.; Wang, Q.; Li, F.; Jiang, L.; Xie, Q. TRAF family proteins regulate autophagy dynamics by modulating AUTOPHAGY PROTEIN6 stability in Arabidopsis. Plant Cell 2017, 29, 890-911. [CrossRef]

57. Hafrén, A.; Macia, J.L.; Love, A.J.; Milner, J.J.; Drucker, M.; Hofius, D. Selective autophagy limits cauliflower mosaic virus infection by NBR1-mediated targeting of viral capsid protein and particles. Proc. Natl. Acad. Sci. USA 2017, 114, E2026-E2035. [CrossRef]

58. Svenning, S.; Lamark, T.; Krause, K.; Johansen, T. Plant NBR1 is a selective autophagy substrate and a functional hybrid of the mammalian autophagic adapters NBR1 and p62/SQSTM1. Autophagy 2011, 7, 993-1010. [CrossRef]

59. Minina, E.A.; Moschou, P.N.; Vetukuri, R.R.; Sanchez-Vera, V.; Cardoso, C.; Liu, Q.; Elander, P.H.; Dalman, K.; Beganovic, M.; Yilmaz, J.L. Transcriptional stimulation of rate-limiting components of the autophagic pathway improves plant fitness. J. Exp. Bot. 2018, 69, 1415-1432. [CrossRef]

60. Klionsky, D.J.; Schulman, B.A. Dynamic regulation of macroautophagy by distinctive ubiquitin-like proteins. Nat. Struct. Mol. Biol. 2014, 21, 336-345. [CrossRef] 
61. Masclaux-Daubresse, C.; Chen, Q.; Havé, M. Regulation of nutrient recycling via autophagy. Curr. Opin. Plant Biol. 2017, 39, 8-17. [CrossRef] [PubMed]

62. Izumi, M.; Ishida, H. Autophagy contributes to nighttime energy availability for growth in Arabidopsis. Plant Physiol. 2013, 161, 1682-1693. [CrossRef] [PubMed]

63. Sun, X.; Jia, X.; Huo, L.; Che, R.; Gong, X.; Wang, P.; Ma, F. MdATG18a overexpression improves tolerance to nitrogen deficiency and regulates anthocyanin accumulation through increased autophagy in transgenic apple. Plant Cell Environ. 2018, 41, 469-480. [CrossRef] [PubMed]

64. Thompson, A.R.; Doelling, J.H.; Suttangkakul, A.; Vierstra, R.D. Autophagic nutrient recycling in Arabidopsis directed by the ATG8 and ATG 12 conjugation pathways. Plant Physiol. 2005, 138, 2097-2110. [CrossRef]

65. Kurusu, T.; Koyano, T.; Hanamata, S.; Kubo, T.; Noguchi, Y.; Yagi, C.; Nagata, N.; Yamamoto, T.; Ohnishi, T.; Okazaki, Y. OsATG7 is required for autophagy-dependent lipid metabolism in rice postmeiotic anther development. Autophagy 2014, 10, 878-888. [CrossRef] [PubMed]

66. Avin-Wittenberg, T.; Baluška, F.; Bozhkov, P.V.; Elander, P.H.; Fernie, A.R.; Galili, G.; Hassan, A.; Hofius, D.; Isono, E.; Bars, R.L.; et al. Autophagy-related approaches for improving nutrient use efficiency and crop yield protection. J. Exp. Bot. 2018, 69, 1335-1353. [CrossRef]

67. Ren, C.; Liu, J.; Gong, Q. Functions of autophagy in plant carbon and nitrogen metabolism. Front. Plant Sci. 2014, 5, 301. [CrossRef]

68. Xu, F.; Meng, T.; Li, P.; Yu, Y.; Cui, Y.; Wang, Y.; Gong, Q.; Wang, N. A soybean dual-specificity kinase, GmSARK, and its Arabidopsis homolog, AtSARK, regulate leaf senescence through synergistic actions of auxin and ethylene. Plant Physiol. 2011, 157, 2131-2153. [CrossRef]

69. Martin, K.; Kopperud, K.; Chakrabarty, R.; Banerjee, R.; Brooks, R.; Goodin, M.M. Transient expression in Nicotiana benthamiana fluorescent marker lines provides enhanced definition of protein localization, movement and interactions in planta. Plant J. 2009, 59, 150-162. [CrossRef]

(C) 2019 by the authors. Licensee MDPI, Basel, Switzerland. This article is an open access article distributed under the terms and conditions of the Creative Commons Attribution (CC BY) license (http://creativecommons.org/licenses/by/4.0/). 